declared, Oliver Distler Grant/research support from: Prof. Distler received research funding from Actelion, Bayer, Boehringer Ingelheim and Mitsubishi Tanabe to investigate potential treatments of scleroderma and its complications, Consultant for: Prof. Distler has/had consultancy relationship within the last 3 years with Actelion, AnaMar, Bayer, Boehringer Ingelheim, ChemomAb, espeRare foundation, Genentech/Roche, GSK, Inventiva, Italfarmaco, iQvia, Lilly, medac, Medlmmune, Mitsubishi Tanabe Pharma, Pharmacyclics, Novartis, Pfizer, Sanofi, Serodapharm and UCB in the area of potential treatments of scleroderma and its complications. In addition, he had/has consultancy relationship within the last 3 years with A. Menarini, Amgen, Abbvie, GSK, Mepha, MSD, Pfizer and UCB in the field of arthritides and related disorders, Britta Maurer Grant/research support from: Grant/research support from AbbVie, Protagen, Novartis; congress support from MSD, Pfizer, Roche, and Actelion, Marco MatucciCerinic Grant/research support from: Actelion, MSD, Pfizer, BMS, Chemomab, Sanipedia, Speakers bureau: Actelion, BMS; MSD, Janssen, Serena Guiducci: None declared, Gabriela Riemekasten Consultant for: Chugai, F. Hoffmann-La Roche, Speakers bureau: Chugai, F. Hoffmann-La Roche, Elise Siegert Shareholder of: Astra Zeneca, Grant/research support from: Actelion, Consultant for: AEC Partners, Speakers bureau: Actelion, Norsk, Ulrich Walker Grant/research support from: Unrestricted grant from AbbVie for the creation of the COmPASS II app, Veronika Jaeger Grant/research support from: Has received an unrestricted grant from AbbVie to support the creation of the COmPASS II app, Marc Frerix: None declared, Ingo Helmut Tarner: None declared, Ulf Müller-Ladner Grant/research support from: Projekt supported by an unrestricted educational grant from Celgene GmbH., Gabriele Valentini Grant/research support from: MSD, Phizer, Consultant for: MSD, Phizer, biogen, Speakers bureau: MSD, amgen, biogen, lilly, sanofi, phizer

DOI: 10.1136/annrheumdis-2019-eular.4784

\section{SAT0255 EVALUATION OF THE CARDIOVASCULAR INVOLVEMENT OF SYSTEMIC SCLEROSIS USING NON- INVASIVE CARDIAC IMAGING TECHNIQUES}

Carina Espinet ${ }^{1,1}$,Maria Nazarena Pizzi ${ }^{1}$, Alfredo Guillén del Castillo ${ }^{1}$, Albert Roque ${ }^{1}$, Victor Pineda ${ }^{1}$, Isidro Sanz ${ }^{1}$, Eduardo L. Callejas-Moraga ${ }^{2}$, Maria Roca ${ }^{1}$, Santiago Aguade ${ }^{1}$, Carmen Pilar Simeón-Aznar ${ }^{1} .{ }^{1}$ Hospital Universitari Vall Hebron, Barcelona, Spain; ${ }^{2}$ Parc Tauli Hospital, Badalona, Spain

Background: Systemic sclerosis (SSc) is a systemic disease that may affect many organs; among them, cardiac involvement. The prevalence of cardiac involvement in SSc varies depending on the sensitivity of the methods used for its detection. Indirect evidence suggests that subclinical cardiac involvement may eventually occur in the vast majority of patients with SSc. Early detection and monitoring of myocardial involvement are integral to SSc management, as cardiovascular involvement is known to be a poor prognostic indicator when present

Objectives: To describe myocardial perfusion abnormalities and potentially associated coronary arteries lesions using non-invasive imaging techniques in a group of patients with SSc and suggestive symptoms of myocardial involvement (symptomatic) in comparison with a control group of patients with SSc without cardiac symptoms

Methods: A retrospective observational study was performed including a total of 61 patients diagnosed with SSc, 52 symptomatic, with dyspnea and/or chest pain (57.98 \pm 12.3 years, 45 women) and 9 asymptomatic controls (50.2 \pm 15.21 years, 8 women).

All patients underwent a post-stress (treadmill or pharmacological) myocardic perfusion gated-SPECT, a cold-induced stress SPECT, that were compared to a rest SPECT (to assess ischemia and/or necrosis), as well as a cardiac CT-angiography (to asses significant coronary arteries lesions, considering stenosis of more than $50 \%$ )

Results: Twenty-one out of the 52 symptomatic patients $(50 \%)$ showed myocardial perfusion defects in the stress-rest SPECT: $13(25 \%)$ showed ischemia, $13(25 \%)$ fibrosis/necrosis, and 5 (9.6\%) ischemia and necrosis. In the cold-induced SPECT, 17 patients (32.7\%) had myocardial perfusion abnormalities: 10 (19.2\%) showed ischemia, 13 (25\%) fibrosis/necrosis and $6(11.5 \%)$ ischemia and necrosis.

In the other hand, of the 9 asymptomatic patients only 1 (11\%) had ischemia and necrosis in the stress-rest SPECT, being only positive for necrosis in the cold-induced SPECT images.

In the cardiac CT-angiography, $7 / 52$ patients (13.4\%) showed significant coronary lesions, $4(57.2 \%)$ of them with perfusion defects in the SPECT images, and $3(42.8 \%)$ without significant perfusion alterations

Of the 9 asymptomatic patients, $1(11 \%)$ had significant coronary lesions, being the same patient who presented perfusion defects in myocardial SPECT images
Conclusion: The gated-SPECT is a sensitive tool for detecting myocardial perfusion alterations, normally with no associated significant coronary lesions, suggesting microvascular abnormalities. In this cohort, myocardia perfusion abnormalities were detected in $50 \%$ of symptomatic patients, whereas in only $11 \%$ of non-symptomatic patients

\section{REFERENCES}

[1] Fernández-Codina A, Simeón-Aznar CP2, Pinal-Fernandez I, RodríguezPalomares J, Pizzi MN, Hidalgo CE, Guillén-Del Castillo A, Prado-Galbarro FJ, Sarria-Santamera A, Fonollosa-Plà V, Vilardell-Tarrés M. Cardiac involvement in systemic sclerosis: differences between clinical subsets and influence on survival. Rheumatol Int. 2017 Jan;37(1):75-84 doi: 10.1007/s00296-015-3382-2. Epub 2015 Oct 25.

[2] Rangarajan V, Matiasz R, Freed BH. Cardiac complications of systemic sclerosis and management: recent progress. Curr Opin Rheumatol. 2017 Nov;29(6):574-584. doi: 10.1097/BOR.

Disclosure of Interests: None declared

DOI: 10.1136/annrheumdis-2019-eular.5492

\section{SAT0256 EFFICACY AND SAFETY OF ANTIFIBROTIC THERAPY IN DIFFUSE INTERSTITIAL PULMONARY DISEASE ASSOCIATED WITH SYSTEMIC AUTOIMMUNE DISEASES}

Marta Aguilar-Zamora ${ }^{1}$, J. Narváez ${ }^{2}$, Juanjo J. Alegre-Sancho ${ }^{1}$, Vanesa Vicens ${ }^{3}$, Maria Molina ${ }^{3}$, Joan Miquel Nolla ${ }^{2} .{ }^{1}$ Hospital Universitari Dr. Peset, Rheumatology, Valencia, Spain; ${ }^{2}$ Hospital Universitari de Bellvitge, Rheumatology, Bellvitge, Spain; ${ }^{3}$ Hospital Universitari de Bellvitge, Pneumology, Bellvitge, Spain

Objectives: Assess the efficacy and safety of antifibrotic agents (pirfenidone and nintedanib) in refractory diffuse interstitial lung disease (DILD) associated with systemic autoimmune diseases (SAD).

Methods: Open observational study in patients with active symptomatic DILD-SAD (evidence of clinical and functional impairment) despite treatment with glucocorticoids (GC) and immunosuppressant therapy.

Results: We included 13 patients (8 women) with a mean age ( \pm SD) of $55 \pm 12$ years (range, 27-71). The baseline SAD were: eighth systemic sclerosis, one rheumatoid arthritis, one ankylosing spondylitis, one microscopic polyangiitis with pulmonary fibrosis and one interstitial lung disease with autoimmune characteristics (IPAF). Mean time from diagnosis to initiation of antifibrotic therapy was $3 \pm 8.2$ years (IQR 25-75\%: $1.6-9.5$ ). The histopathological patterns found were: seven cases $(54 \%)$ of usual interstitial pneumonia (UIP), three (23\%) nonspecific interstitial pneumonia (NSIP), two cases (15\%) combined pattern of pulmonary fibrosis plus emphysema (CPFE), and one (8\%) non-classifiable pulmonary fibrosis (without histospecific radiological pattern).

In addition to GC, the previous therapy tested for DIDL was mycophenolate mofetil (MMF) in $77 \%$ of the patients, cyclophosphamide (8 intravenous boluses) in $46 \%$, and rituximab (RTX) in $54 \%$ (the number of RTX cycles administered were $4 \pm 3.3$; range, 1-9). Despite this, during the year prior to start the antifibrotic drugs, all patients presented a worsening in the values of $\%$ pFVC $(-8.77 \%)$ and\% pDLCO $(-12.41 \%)$.

Five (38\%) patients received pirfenidone at doses of 3 tablets $/ 8$ hours (2403 mg/day) and eight (62\%) nintedanib (5 at a dose of $150 \mathrm{mg} / 12$ hours and 3 at a dose of $100 \mathrm{mg} / 12$ hours).

Antifibrotic therapy was administered in combination with MMF (1.5-2 g/ day) in 10 patients (77\%) and with rituximab in $3(23 \%)$, in addition to $\mathrm{GC}$ at doses between 5 and $20 \mathrm{mg} /$ prednisone per day. The mean

\begin{tabular}{|l|c|c|c|c|}
\hline & $\begin{array}{c}\text { Pre-treatment } \\
\text { (mean } \pm \text { SD) }\end{array}$ & $\begin{array}{c}\text { Post-treatment } \\
\text { (mean } \pm \text { SD) }\end{array}$ & \multicolumn{2}{c|}{$\begin{array}{c}\text { Delta } \\
\text { (mean) }\end{array}$} \\
\hline$\%$ pFVC & $67.9 \pm 15.6$ & $74.2 \pm 13.9$ & +5.13 & NS \\
\hline$\%$ pTLC & $66 \pm 10.8$ & $77 \pm 15.55$ & +4.86 & NS \\
\hline \%pDLCO & $37.8 \pm 7.22$ & $44 \pm 7.32$ & +4.42 & NS \\
\hline Walking (meters) & $409 \pm 52$ & $415 \pm 103$ & +7.57 & NS \\
\hline
\end{tabular}

The response in the Pulmonary function testing (PFT) in these 9 patients categorized according to the definitions of the American Thoracic Society was as follows: A)\% pFVC: stabilization in 5 cases and improvement in 4; B)\% pDLCO: stabilization in 7 cases and improvement in 3 . 